\title{
Effects of selected insecticides on osmotically treated entomopathogenic nematodes
}

\author{
Xun Yan1,2, Maurice Moens 2,3 , Richou Han', Shulong Chen4 \& Patrick De Clercq2,* \\ 1 Guangdong Entomological Institute, 105 Xingang Road West, Guangzhou, 510260 China \\ 2 Department of Crop Protection, Ghent University, Coupure Links 653, B-9000 Ghent, Belgium \\ 3 Institute for Agricultural and Fisheries Research, Burg. Van Gansberghelaan 96, B-9280 Merelbeke, Belgium \\ 4 Plant Protection Institute of Hebei Academy of Agricultural and Forestry Sciences, 437 Dongguan Street, 071000 Baoding, China \\ * Corresponding author: Patrick.DeClercqa)UGent.be
}

Received 11 May 2012, accepted 13 August 2012

\begin{abstract}
Combining environmentally friendly insecticides with entomopathogenic nematodes may constitute an effective alternative to conventional chemical control of many insect pests. The objective of this laboratory study was to evaluate the effects of selected insecticides which are commonly used for pest control in vegetables in China on osmotically treated and untreated infective juveniles of Steinernema carpocapsae strain All. The insecticides azadirachtin, chlorpyrifos, cypermethrin, fipronil, imidacloprid, malathion, thiamethoxam and chlorantraniliprole-thiamethoxam had no adverse effects on nematode survival and infectivity. In contrast, bisultap, emamectin benzoate, phoxim and rotenone proved harmful to $S$. carpocapsae All mainly by reducing infectivity of the infective juveniles to larvae of the greater wax moth, Galleria mellonella. Osmotic induction is a promising way to induce entomopathogenic nematodes into partial anhydrobiosis and thus increase environmental stress tolerance of the nematodes as well as their shelf life after production. The present results showed that osmotic treatment did not adversely affect fitness of the nematode in terms of its susceptibility to insecticides and even increased its tolerance to chlorpyrifos and rotenone. The results of this laboratory study indicate that several of the tested insecticides can be safely combined with $S$. carpocapsae All within an integrated pest management approach.
\end{abstract}

Key words: Integrated pest management, osmotic treatment, Steinernema carpocapsae

\section{Introduction}

Chemical insecticides are the main method for many insect pests control in crops, vegetables and fruits in China. Heavy use of chemical insecticides leads to operator and consumer poisoning, hampers export of the products, and causes serious environmental pollution (Wang \& Han 2008). With the development of insecticide resistance due to the high frequency of insecticide applications (Feng et al. 2000), environmentally friendly control methods are urgently needed.

Entomopathogenic nematodes (EPN) of the genera Steinernema and Heterorhabditis (Rhabditida: Steinernematidae and Heterorhabditidae) are natural enemies of various insect pests. They can actively search for their hosts in the soil (Grewal et al. 2005) and can be easily mass-produced using conventional fermentation technology (Grewal et al. 2002). They are increasingly used to control insect crop pests in different parts of the world (Kaya et al. 2006). In comparison with common chemical insecticides, however, the cost of EPN remains too high for the average Chinese grower. Combining EPN with insecticides has contributed to the suppression of a number of economically important crop pests (Koppenhöfer \& Grewal 2005). Such an integrated pest management (IPM) approach could not only yield more effective control and slow down development of insecticide resistance, but could also lower EPN application rates and thus contribute to a reduction of control cost.

EPN can be induced into partial anhydrobiosis. Anhydrobiosis is a state of dormancy induced by dehydration (Barrett 1991). In an anhydrobiotic state, resistance of EPN to environmental extremes, hypoxia, radiation and metabolic poisons lethal to active organisms, is greatly increased (Grewal 2000). A previous study showed that exposure to (hyper)osmotic solutions (termed "osmotic induction") can improve storage stability of Steinernema carpocapsae All (Yan et al. 2011). The nematode can thus be stored after osmotic induction into partial anhydrobiosis and subsequently applied in the field after rehydration.

Improving insight in the response of EPN to insecticide exposure may aid the development of IPM programs against key pests. Therefore, the objective of the present laboratory study was to evaluate the susceptibility of both osmotically treated and untreated $S$. carpocapsae All to selected insecticides which are commonly used for the control of insect pests in vegetable production in China. Survival of infective juveniles (IJ) exposed to the insecticides at different concentrations and their infectivity to larvae of the greater wax moth Galleria mellonella (Lepidoptera: Pyralidae) were evaluated in the laboratory.

\section{Materials and methods}

\section{Nematodes}

Steinernema carpocapsae All was reared from an in vitro solid sponge culture in $1000 \mathrm{ml}$ flasks according to the 
method of Bedding (1981) with modifications (Han 1995). After 4 weeks of incubation at $25^{\circ} \mathrm{C}$, the IJ were soaked out of the sponge and washed with sterile distilled water $(6 \mathrm{x})$, concentrated to $2 \times 10^{4} \mathrm{IJ} \mathrm{ml}^{-1}$ and then stored at $15^{\circ} \mathrm{C}$. The stored IJ were tested within 2 weeks. Background mortality was below $5 \%$ throughout the study.

Osmotic induction of IJ was conducted as described by Yan et al. (2010). The IJ were treated with osmotic solution consisting of a mixture of fortified artificial seawater (1.692 M NaCl, $9.00 \mathrm{mM} \mathrm{KCl}, 9.27 \mathrm{mM} \mathrm{CaCl}_{2}, 22.94 \mathrm{mM}$ $\left.\mathrm{MgCl}_{2} \cdot 6 \mathrm{H}_{2} \mathrm{O}, 25.50 \mathrm{mM} \mathrm{MgSO}_{4} \times 7 \mathrm{H}_{2} \mathrm{O}, 2.14 \mathrm{mM} \mathrm{NaHCO}_{3}\right)$ and glycerol $(6.4 \mathrm{M})$ at a proportion of $1: 5(\mathrm{v} / \mathrm{v})$ in $250 \mathrm{ml}$ flasks and incubated at $15^{\circ} \mathrm{C}$ for $24 \mathrm{~h}$ in a rotary shaker at $100 \mathrm{rpm}$. After that, $1 \mathrm{ml}$ of osmotically treated or untreated nematode suspension was transferred to a $9 \mathrm{~cm}$ Petri dish containing $9 \mathrm{ml}$ sterile distilled water. The dishes were incubated at $25^{\circ} \mathrm{C}$ for $24 \mathrm{~h}$ in order to rehydrate the IJ before exposure to the insecticides. The experiments were repeated twice using different batches of nematodes. Different batches of EPN were cultured at different times throughout the study. They were from the same ancestor but of different generations.

\section{Insects}

The greater wax moth, Galleria mellonella, is a model insect used for EPN bait trapping and for evaluation of EPN infectivity. Galleria mellonella was reared in an environmentally controlled room at $28 \pm 2{ }^{\circ} \mathrm{C}$ and $60 \%$ relative humidity (RH). The larvae were fed on an artificial diet modified from Vanhaecke \& Degheele (1980).

\section{Insecticides}

Insecticides used in the present study are listed in Table 1; all were commercial formulations purchased on the Chinese market and commonly used in Chinese vegetable production.

\section{Effects of insecticides on nematode survival}

Effects of insecticides on nematode survival were tested using the method described by Zhang et al. (2006) with modifications. Insecticide dilutions were prepared in distilled water and added to each Petri dish to a final concentration corresponding with the recommended field concentration (RC), 1/10 RC or 1/50 RC. The insecticide-treated IJ were incubated at $25^{\circ} \mathrm{C}$ in the dark for $24 \mathrm{~h}$. Each treatment had three replicates (dishes) with a density of $1000 \mathrm{IJ} \mathrm{ml}^{-1}$. Infective juveniles treated with osmotic solution or distilled water only were used as controls. After that, three $100 \mu \mathrm{l}$ samples were drawn from each dish and mortality of the IJ was calculated. Infective juveniles were considered dead when showing no response after probing with a needle. The infectivity of the exposed IJ to last instar larvae of G. mellonella was tested as described below when there were surviving IJ.

\section{Effects of insecticides on nematode infectivity}

A Petri dish bioassay was used to estimate the effects of the tested insecticides on nematode infectivity (Zhang et al.

Table 1: Insecticides used in the study

\begin{tabular}{|c|c|c|c|}
\hline Insecticide & Main component & Manufacturer & $\begin{array}{l}\text { Recommended } \\
\text { field rate }\end{array}$ \\
\hline Azadirachtin EC $0.3 \%$ & azadirachtin & Chengdu Green the High-Tech Co., Ltd, Chengdu & $1200 \mathrm{ml} \mathrm{ha}^{-1}$ \\
\hline Bisultap AS $18 \%$ & bisultap & Zhongshan Aestar Fine Chemical Inc., Ltd, Zhongshan & $675 \mathrm{~g} \mathrm{ha}^{-1}$ \\
\hline Virtako WG $40 \%$ & $\begin{array}{l}\text { chlorantraniliprole, } \\
\text { thiamethoxam }\end{array}$ & Syngenta, Beijing & $120 \mathrm{~g} \mathrm{ha}^{-1}$ \\
\hline Lorben EC $40 \%$ & chlorpyrifos & Zhejiang XinNong Chemical Co., Ltd, Hangzhou & $1500 \mathrm{~g} \mathrm{ha}^{-1}$ \\
\hline Cypermethrin EC $4.5 \%$ & beta cypermethrin & Daguangming Nongyao Huagong Co., Ltd, Jiangmen & $600 \mathrm{ml} \mathrm{ha}^{-1}$ \\
\hline Emamectin benzoate EC 2\% & emamectin benzoate & Zhejiang Qianjiang Biochemical Co., Ltd, Haining & $125 \mathrm{ml} \mathrm{ha}^{-1}$ \\
\hline Regent SC $80 \%$ & fipronil & Bayer Cropscience, Hangzhou & $20 \mathrm{~g} \mathrm{ha}^{-1}$ \\
\hline Admire WG $70 \%$ & imidacloprid & Bayer Cropscience, Hangzhou & $20 \mathrm{~g} \mathrm{ha}^{-1}$ \\
\hline Malathion EC 45\% & malathion & Cangzhou Lekai Nongyao Huagong Co., Ltd, Cangzhou & $3000 \mathrm{ml} \mathrm{ha}^{-1}$ \\
\hline Phoxim EC $40 \%$ & phoxim & $\begin{array}{l}\text { Lianyungang Liben Nongyao Huagong Co., Ltd, } \\
\text { Lianyungang }\end{array}$ & $750 \mathrm{ml} \mathrm{ha}^{-1}$ \\
\hline Rotenone EC $2.5 \%$ & rotenone & $\begin{array}{l}\text { Shenzhen Huanong Biological Engineering Co., Ltd, } \\
\text { Shenzhen }\end{array}$ & $2000 \mathrm{~g} \mathrm{ha}^{-1}$ \\
\hline Actara WG $25 \%$ & thiamethoxam & Syngenta, Beijing & $300 \mathrm{~g} \mathrm{ha}^{-1}$ \\
\hline
\end{tabular}

EC, emulsifiable concentrate; AS, aqueous solution; WG, water dispersible granules; SC, suspension concentrate. 
2006). Two layers of $9 \mathrm{~cm}$ filter paper (Xinhua, China) were placed in a $9 \mathrm{~cm}$ Petri dish. Two hundred fifty live IJ were sampled from the Petri dishes in which they had been exposed to insecticide and insecticide dilutions at the respective concentrations (as described before) were added to a final volume of $1.5 \mathrm{ml}$. The $\mathrm{IJ}$ in different dilutions of the selected insecticides were then applied onto the filter paper. Subsequently, ten last instar G. mellonella were placed in each dish. Infective juveniles in distilled water were used as controls. The G. mellonella larvae were also exposed to all concentrations of the selected insecticides and to water only (control), without $S$. carpocapsae. Each treatment had three replicates (dishes). The dishes were sealed with Parafilm (SPI Supplies, West Chester, USA) and incubated at $25^{\circ} \mathrm{C}$ for $72 \mathrm{~h}$. Mortality of the G. mellonella larvae was checked every $12 \mathrm{~h}$ and nematode infectivity was expressed as mortality of wax moth larvae $72 \mathrm{~h}$ after infection.

\section{Statistical analysis}

Nematode and insect mortality data were expressed in percentages. Mortality rates of the IJ were corrected for control mortality using Abbott's formula (Abbott 1925). All data were arcsine square root transformed prior to statistical analysis performed with SPSS 16.0 software (SPSS Inc., Chicago, IL, USA). To assess effects of osmotic treatment, insecticide concentration and their interaction, a Univariate General Linear Model was used. Means were separated using Tukey's test. Paired sample $t$-tests were done to analyse differences between osmotically treated and untreated nematodes exposed to the same concentration of the same insecticide. Differences among means were considered significant at $P<0.05$.

\section{Results}

\section{Effect of insecticides on nematode survival}

Corrected mortality rates of $S$. carpocapsae strain All exposed to different concentrations of the tested insecticides are shown in Fig. 1. Nine of these insecticides (azadirachtin, cholorantraniliprole-thiamethoxam, cypermethrin, malathion, emamectin benzoate, fipronil, phoxim, imidacloprid and thiamethoxam) had no or negligible effects on survival of both osmotically treated and untreated IJ at the different concentrations, with mortality rates below 4\%.

Three insecticides, rotenone, bisultap, and chlorpyrifos, did affect survival of $S$. carpocapsae All to some extent with mortalities ranging from 10 to $58 \%$ for IJ that had not been exposed to the osmotic solution; the effect of osmotic treatment on nematode susceptibility also varied. The effects of osmotic treatment and insecticide concentration on mortality of $S$. carpocapsae All exposed to the latter three insecticides are shown in Table 2. Rotenone was harmful to the IJ at RC with mortality rates of $57.9 \pm 2.2 \%$ (mean $\pm \mathrm{SE}$ ) for untreated IJ and $31.2 \pm 2.3 \%$ for osmotically treated IJ. Bisultap at RC caused $21.1 \pm 3.8 \%$ mortality in untreated IJ
Table 2: Two-way ANOVA results indicating the effect of osmotic treatment and insecticide concentration on infectivity of Steinernema carpocapsae All based on corrected mortality of Galleria mellonella $72 \mathrm{~h}$ post-infection

\begin{tabular}{|c|c|c|c|}
\hline \multirow[t]{2}{*}{ Factor } & \multicolumn{3}{|c|}{ Insecticide } \\
\hline & rotenone & bisultap & chlorpyrifos \\
\hline \multicolumn{4}{|c|}{ Osmotic treatment $(d f=1,12)$} \\
\hline Fvalue & 2.406 & 9.828 & 8.131 \\
\hline$P$-value & 0.147 & 0.009 & 0.015 \\
\hline \multicolumn{4}{|c|}{ Insecticide concentration $(d f=2,12)$} \\
\hline Fvalue & 128.787 & 53.754 & 19.469 \\
\hline$P$-value & $<0.001$ & $<0.001$ & $<0.001$ \\
\hline \multicolumn{4}{|c|}{ Osmotic treatment $\times$ insecticide concentration $(d f=2,12)$} \\
\hline Fvalue & 8.383 & 2.985 & 6.199 \\
\hline$P$-value & 0.005 & 0.089 & 0.014 \\
\hline
\end{tabular}

and $9.9 \pm 1.1 \%$ in osmotically treated IJ. There were no effects of bisultap and rotenone on survival of both osmotically treated and untreated IJ at 1/10 and 1/50 RC. For bisultap and rotenone at RC, mortality of osmotically treated IJ was also higher than 10\%. Chlorpyrifos was slightly harmful to the IJ without osmotic treatment at RC with a mortality rate of $10.0 \pm 1.1 \%$. There were no effects of chlorpyrifos on survival of IJ with osmotic treatment at all three concentrations and without treatment at $1 / 10$ and 1/50 RC.

Osmotically treated IJ showed better survival than untreated IJ in insecticide solutions of chlorpyrifos, rotenone and emamectin benzoate. Mortality rates of osmotically treated IJ were significantly lower than those of the untreated IJ exposed to chlorpyrifos $(t=5.718 ; d f=2 ; P=0.035)$, rotenone $(t=6.427 ; d f=2 ; P=0.023)$ and emamectin benzoate $(t=5.810 ; d f=2 ; P=0.028)$.

\section{Effect of insecticides on nematode infectivity}

Corrected mortality rates of $G$. mellonella $72 \mathrm{~h}$ after exposure to $S$. carpocapsae All in different dilutions of the selected insecticides are shown in Table 3. For the insecticides alone, only RC of emamectin benzoate caused significant mortality in $G$. mellonella, with an average of $43 \%$ after $72 \mathrm{~h}$, indicating the low susceptibility of the exposed last instar larvae of this insect to the tested insecticide concentrations. For the nematodes in different dilutions of the tested insecticides, there were no effects on IJ infectivity for azadirachtin, chlorantraniliprole-thiamethoxam, chlorpyrifos, cypermethrin, fipronil, imidacloprid, malathion and thiamethoxam, which caused about $100 \%$ mortality of $G$. mellonella in $48-72 \mathrm{~h}$, as did osmotically treated or untreated IJ alone.

Mortality rates of $G$. mellonella exposed to $S$. carpocapsae All in solutions of four insecticides (bisultap, emamectin benzoate, phoxim and rotenone) were significantly influenced by insecticide concentration but not by osmotic treat- 


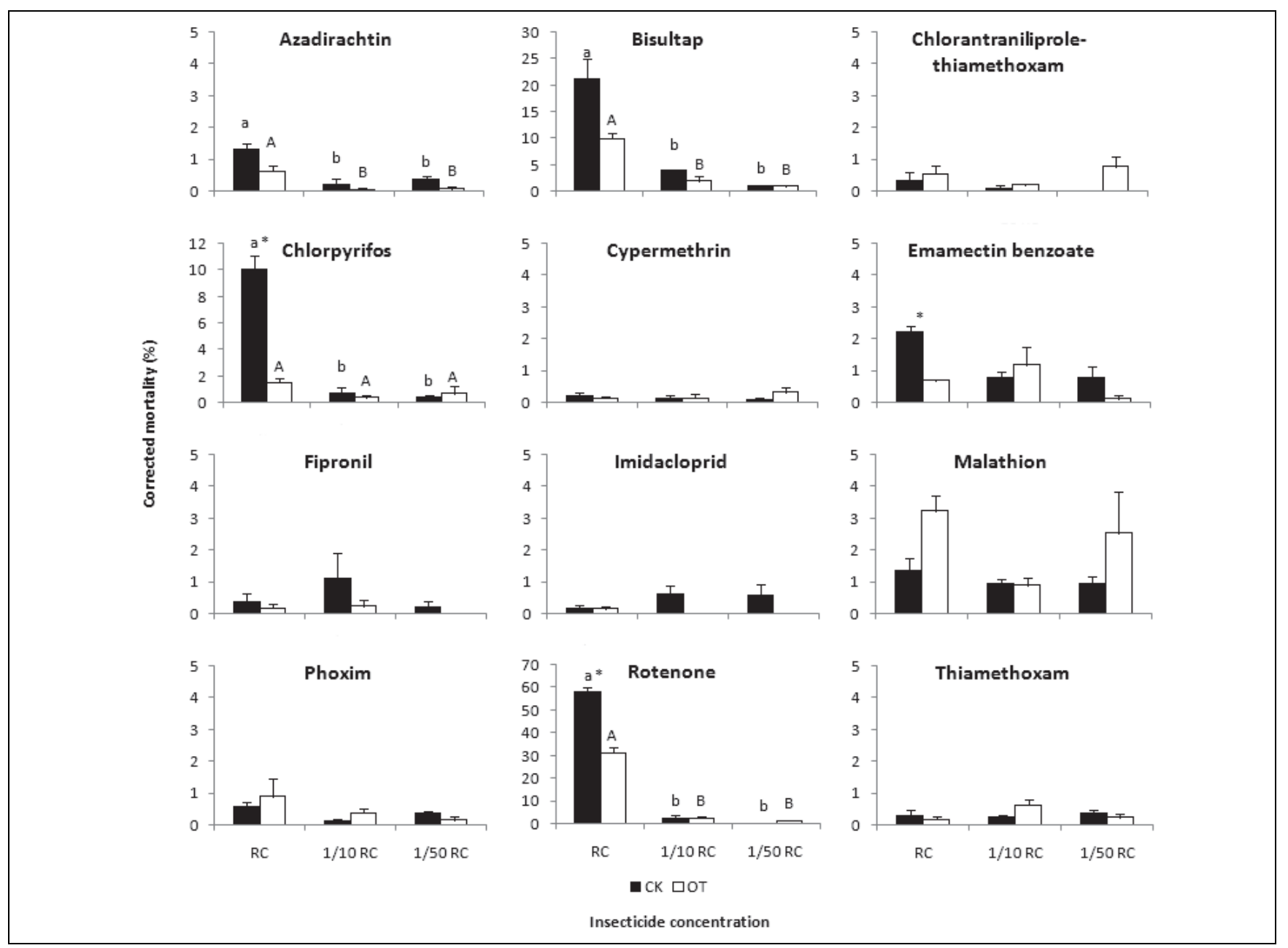

Fig. 1: Corrected mortality rates $( \pm \mathrm{SE})$ of osmotically treated and untreated Steinernema carpocapsae All after exposure to different insecticides at different concentrations.

CK, untreated S. carpocapsae All; OT, osmotically treated S. carpocapsae All. RC, recommended concentration; 1/10 RC, 10-time diluent of recommended concentration; $1 / 50$ RC, 50-time diluent of recommended concentration. Asterisks (*) above bars indicate a significant difference of mortality rates between the osmotically treated and untreated nematodes treated with the same concentration of insecticide $(P<0.05)$. Bars with different uppercase or lowercase letters indicate significant differences in mortality rates among different concentrations of insecticides for osmotically treated or untreated nematodes, respectively $(P<0.05$, Tukey's test).

ment and the interaction between the two factors was also not significant (Table 4). Infective juveniles treated with bisultap at the RC lost their infectivity to $G$. mellonella, but retained their infectivity when treated at $1 / 10$ or $1 / 50 \mathrm{RC}$. Infective juveniles exposed to emamectin benzoate at RC and 1/10 RC showed weaker infectivity to G. mellonella when compared with IJ without insecticide treatments. At $\mathrm{RC}$ and 1/10 RC of latter compound, G. mellonella mortality caused by untreated and osmotically treated IJ at $72 \mathrm{~h}$ averaged $47-63 \%$, but reached $100 \%$ at $1 / 50$ RC. Exposure of IJ to phoxim and rotenone at the three different concentrations greatly reduced their infectivity to $G$. mellonella.

\section{Discussion}

Combining the use of biological control agents, like EPN, with insecticides is central to IPM programs against many agricultural pests (Koppenhöfer \& Grewal 2005). This strategy can not only facilitate the use of EPN, increase the control efficiency of programs including EPN and reduce the cost of EPN application, but it may also reduce the dependence on chemical insecticides and thus contribute to slowing down the development of insecticide resistance and preventing adverse effects on man and the environment. The present laboratory study explored the effects of several commonly used insecticides in China on osmotically treated and untreated IJ of $S$. carpocapsae All and indicated that some of these insecticides may be harmless to the nematode.

Commercial formulations of azadirachtin, chlorantraniliprole, chlorpyrifos, cypermethrin, fipronil, malathion, imidacloprid and thiamethoxam showed no negative effects on the survival and infectivity of both osmotically treated and untreated $S$. carpocapsae All. The results are consistent with those from former studies on the compatibility of $S$. carpocapsae with thiamethoxam, imidacloprid, azadirachitin, 
Table 3: Corrected mortality rates of Galleria mellonella larvae $72 \mathrm{~h}$ after exposure to Steinernema carpocapsae All in different concentrations of selected insecticides

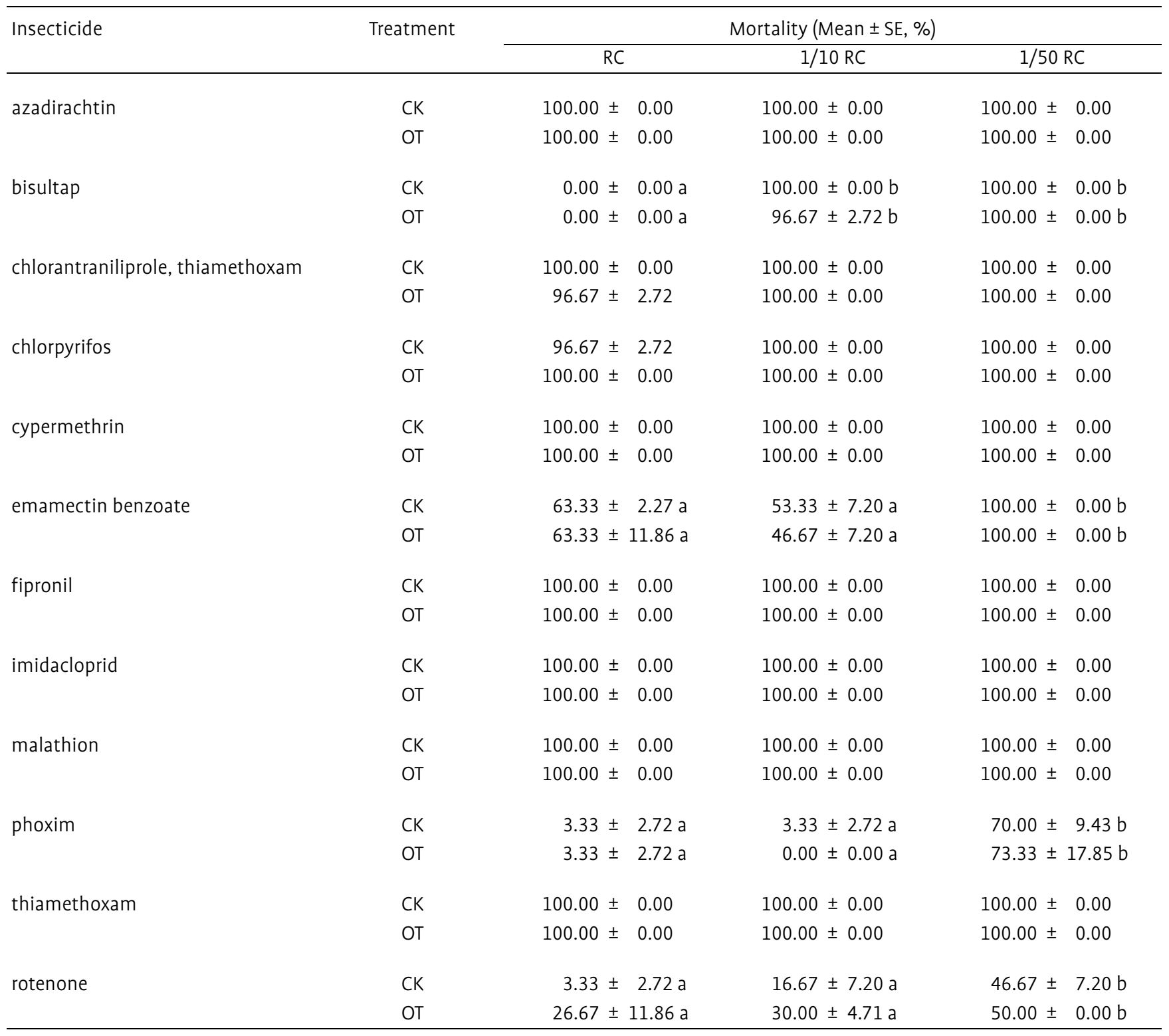

CK, untreated S. carpocapsae All; OT, osmotically treated S. carpocapsae All. RC, recommended concentration; 1/10 RC, 10-time diluent of the recommended concentration; 1/50 RC, 50-time diluent of the recommended concentration. Means within a row followed by different letters are significantly different $(P<0.05$, Tukey's test).

fipronil and chlorpyrifos (Prakasa Rao et al. 1975, Rovesti et al. 1988, Koppenhöfer et al. 2003, Alumai \& Grewal 2004, García del Pino \& Jové 2005, Negrisoli Jr et al. 2010). Cypermethrin caused $12 \%$ mortality in S. carpocapsae in a study by Negrisoli Jr et al. (2010), whereas in our study mortality of $S$. carpocapsae caused by cypermethrin remained below 1\%. Emamectin is fermented from Streptomyces avermitilis and is generally formulated as emamectin benzoate (Waddy et al. 2007). According to Fetoh et al. (2009) emamectin benzoate had no adverse effects on $S$. carpocapsae and a mixture of $S$. carpocapsae with formulated emamectin benzoate significantly increased mortality to greasy cutworm (Agrotis ipsilon) as compared with S. carpocapsae alone. In our study, however, viability of $S$. carpocapsae IJ was not affected by emamectin benzoate, but their infectivity was impaired. Different findings among studies may be related to differences in formulation of the test compounds and in the experimental design (Koppenhöfer \& Grewal 2005, Negrisoli Jr et al. 2010).

No studies have previously reported on the compatibility of $S$. carpocapsae with bisultap, malathion, phoxim and rotenone. The nereistoxin bisultap is a broad-spectrum insecticide with a strong stomach, contact, systemic and fumigant activity (Wang et al. 1995). Bisultap proved toxic to $S$. carpocapsae All only when applied at RC. At lower concentrations, however, adverse effects of bisultap in our 
Table 4: Two-way ANOVA results indicating the effect of osmotic treatment and insecticide concentration on infectivity of Steinernema carpocapsae All based on corrected mortality of Galleria mellonella $72 \mathrm{~h}$ post-infection

\begin{tabular}{|c|c|c|c|c|}
\hline \multirow[b]{2}{*}{ Factor } & \multicolumn{4}{|c|}{ Insecticide } \\
\hline & bisultap & $\begin{array}{c}\text { emamectin } \\
\text { benzoate }\end{array}$ & phoxim & rotenone \\
\hline \multicolumn{5}{|c|}{ Osmotic treatment $(d f=1,12)$} \\
\hline Fvalue & 1.000 & 0.059 & 0.002 & 3.892 \\
\hline$P$-value & 0.337 & 0.812 & 0.963 & 0.066 \\
\hline \multicolumn{5}{|c|}{ Insecticide concentration $(d f=2,12)$} \\
\hline F-value & 829.740 & 61.808 & 64.477 & 167.695 \\
\hline$P$-value & $<0.001$ & $<0.001$ & $<0.001$ & $<0.001$ \\
\hline \multicolumn{5}{|c|}{ Osmotic treatment $\times$ insecticide concentration $(d f=2,12)$} \\
\hline Fvalue & 1.000 & 0.137 & 0.261 & 1.081 \\
\hline$P$-value & 0.397 & 0.936 & 0.852 & 0.385 \\
\hline
\end{tabular}

laboratory exposure tests were negligible. The organophosphate insecticide phoxim had no effects on the survival of S. carpocapsae All, but strongly reduced the infectivity of IJ, even at diluted concentrations. Rotenone has been widely used in organic farming in China to control leaf feeding pests, including flea beetles on brassicas. Rotenone kills fishes and other organisms by blocking the cellular uptake of oxygen (Singer \& Ramsay 1994). However, it is rapidly bio-degraded under warm conditions and is poorly absorbed by the gastrointestinal tract of humans, rendering it relatively safe to man and the environment (Ling 2003, Robertson \& Smith-Vaniz 2008). In our study, the compound proved lethal to S. carpocapsae All at RC, with $58 \%$ and $31 \%$ mortality of untreated and osmotically treated IJ, respectively, and it impaired the infectivity of the nematode even at very low concentrations (1/10 RC and 1/50 RC). The adverse effects of the insecticides tested in the present study on $S$. carpocapsae may be due to the direct toxicity of the active ingredient to the nematode or to the detrimental effects of the formulation on the symbiotic bacteria (Alumai \& Grewal 2004, Hara \& Kaya 1983).

Our results further indicate that osmotic treatment did not adversely affect fitness of the nematode in terms of its susceptibility to insecticides. Interestingly, an increase in tolerance of the IJ to chlorpyrifos and rotenone was observed when exposed to osmotic induction. Such an effect could not be demonstrated for the other insecticides, given the low mortality rates observed in our experiments. EPN can be induced into a state of partial anhydrobiosis using osmotic solutions, which may allow longer storage of the IJ (Feng et al. 2006). Molecular studies indicated that in response to desiccation and osmotic induction of anhydrobiosis, the expression of certain genes was up-regulated and some novel proteins were induced (Yan \& Han 2010). After dehydration and the subsequent rehydration, these genes and proteins may still be in function, enabling the EPN to better resist environmental stresses including that from toxic substances. This may explain why the osmotically treated $S$. carpocapsae exposed to chlorpyrifos and particularly rotenone survived better than untreated ones.

In conclusion, the present laboratory study indicates that azadirachtin, chlorantraniliprole, chlorpyrifos, cypermethrin, fipronil, malathion, imidacloprid and thiamethoxam are harmless to IJ of $S$. carpocapsae All. However, laboratory and field studies using target insects are needed to confirm whether these compounds can be safely applied together with $S$. carpocapsae All for the control of insect pests in vegetable crops in China and beyond.

\section{Acknowledgements}

This study was supported by the VLIR (Belgium) own initiatives programme ENCHIBE (Entomopathogenic nematodes for sustainable control of chive midge and flea beetle in China, VLIR reference ZEIN2007PR339), the Young Scientist Foundation of the Guangdong Academy of Sciences (qnjj200910), National High-Technology Research and Development Project (863 Project) (2011AA10A201), Guangdong Provincial Science \& Technology Project (2009B091300015, 2009B050700033, 2010B050300017, 2011B040300013), Nonprofit sector project (201003025), Guangzhou Science \& Technology Project (2011J2200032), National Natural Science Foundation of China (31010103912) and Young Scientists Fund of National Natural Science Foundation of China (31101494).

\section{References}

Abbott WS, 1925. A method of computing the effectiveness of an insecticide. J Econ Entomol 18, 265-267.

Alumai A \& Grewal PS, 2004. Tank-mix compatibility of the entomopathogenic nematodes, Heterorhabditis bacteriophora and Steinernema carpocapsae, with selected chemical pesticides used in turf grass. Biocontrol Sci Technol 14, 725-730.

Barrett J, 1991. Anhydrobiotic nematodes. Agr Zool Rev 4, 161-175.

Bedding RA, 1981. Low cost in vitro mass production of Neoaplectana and Heterorhabditis species (Nematoda) for field control of insect pests. Nematologica 27, 109-114.

Feng HT, Huang YJ \& Hsu JC, 2000. Insecticide susceptibility of cabbage flea beetle (Phyllotreta striolata (Fab.)) in Taiwan. Plant Prot Bull Taipei 42, 123-146.

Feng SP, Han RC, Qiu XH, Cao L, Chen JH \& Wang GH, 2006. Storage of osmotically treated entomopathogenic nematode Steinernema carpocapsae. Insect Sci 13, 263-269.

Fetoh BES, Khaled AS \& El-Nagar TFK, 2009. Combined effect of entomopathogenic nematodes and biopesticides to control the greasy cut worm, Agrotis ipsilon (Hufn.) in the strawberry fields. Egypt Acad J Biol Sci 2 (1), 227-236.

García del Pino F \& Jové M, 2005. Compatibility of entomopathogenic nematodes with fipronil. J Helminthol 79, 333-337. 
Grewal PS, 2000. Enhanced ambient storage stability of an entomopathogenic nematode through anhydrobiosis. Pest Manag Sci 56, 401-406.

Grewal PS, Wang X \& Taylor RAJ, 2002. Dauer juvenile longevity and stress tolerance in natural populations of entomopathogenic nematodes: is there a relationship? Int J Parasitol 32, 717-725.

Grewal PS, Ehlers RU \& Shapiro-Ilan DI, 2005. Nematodes as Biocontrol Agents. CABI, New York, NY.

Han RC, 1995. Optimum management of mass production system of entomopathogenic Steinernema and Heterorhabditis nematodes. PhD Thesis, South China Agricultural University Press, Guangzhou, P.R. China.

Hara AH \& Kaya HK, 1983. Toxicity of selected organophosphate and carbamate pesticides to infective juveniles of the entomogenous nematode Neoaplectana carpocapsae (Rhabditida: Steinernematidae). Environ Entomol 12, 496-501.

Kaya HK, Alunmai A, Choo HY, De La Torre M, Fodor A, Ganguly S, Hazir S, Lakatos T, Pye A, Wilson M, Yamanaka S, Yang H \& Ehlers RU, 2006. Status of entomopathogenic nematodes and their symbiotic bacteria from selected countries or regions of the world. Biol Control 38, 134-155.

Koppenhöfer AM \& Grewal PS, 2005. Compatibility and interactions with agrochemicals and other biocontrol agents. In: Grewal PS, Ehlers R \& Shapiro-Ilan DI (Eds.) 2005. Nematodes as Biocontrol Agents. CABI Publishing, Wallingford, Oxfordshire, UK. 363-381.

Koppenhöfer AM, Cowles RS, Cowles EA, Fuzy EM \& Baumgartner L, 2003. Effect of neonicotinoid insecticide synergists on entomopathogenic nematode fitness. Entomol Exp Appl 106, 7-18.

Ling N, 2003. Rotenone - a review of its toxicity and use for fisheries management. Wellington (New Zealand): Department of Conservation. Science for Conversation No. 211.

Negrisoli Jr AS, Garcia MS \& Negrisoli CRCB, 2010. Compatibility of entomopathogenic nematodes (Nematoda: Rhabditida) with registered insecticides for Spodoptera frugiperda (Smith, 1979) (Lepidoptera: Noctuidae) under laboratory conditions. Crop Prot 29, 545-549.
Prakasa Rao PS, Das PK \& Pandhi G, 1975. Note of compatibility of DD-136 (Neoaplectana dutkyi), an insect parasitic nematode with some insecticides and fertilizers. Indian J Agr Sci (publ. 1977) 45, 275-277.

Robertson DR \& Smith-Vaniz WF, 2008. Rotenone: An essential but demonized tool for assessing marine fish diversity. Bioscience 58, 165-170.

Rovesti L, Heinzpeter EW, Tagliente F \& Deseö KV, 1988. Compatibility of pesticides with the entomopathogenic nematodes Heterorhabditis bacteriophora Poinar (Nematoda: Heterorhabditidae). Nematology 34, 462-476.

Singer TP \& Ramsay RR, 1994. The reaction site of rotenone and ubiquinone with mitochondrial NADH dehydrogenase. Biochim Biophys Acta 1187, 198-202.

Vanhaecke M \& Degheele D, 1980. Electrophoretic characterization of the haemolymph proteins, glyco- and lipoproteins of Galleria mellonella, Plodia interpunctella and Ephestia kuehniella. Meded Fac Landbouww Rijksuniv Gent 45, 1287-1297.

Waddy S, Merritt V, Hamilton-Gibson M, Aiken D \& Burridge L, 2007. Relationship between dose of emamectin benzoate and molting response of ovigerous American lobsters (Homarus americanus). Ecotoxicol Environ Saf 67, 95-99.

Wang G \& Han R, 2008. Biological control of striped flea beetle, Phyllotreta striolata Fabricius. Chinese J Biol Control 24 (1), 91-93.

Wang X, Zhao Y, Feng Y, Chen H, Lin Y \& Han Q, 1995. Analysis of blood, stomach and liver samples from Shachongshuang intoxicated persons. J Hyg Res 24, 346-349.

Yan X \& Han RC, 2010. Anhydrobiosis of entomopathogenic nematodes. Chinese J Biol Control 26, 90-95.

Yan X, Liu X, Han R, Chen S, De Clercq P \& Moens M, 2010. Osmotic induction of anhydrobiosis in entomopathogenic nematodes of the genera Heterorhabditis and Steinernema. Biol Control 53, 325-330.

Yan X, De Clercq P, Han R, Jones J, Chen S \& Moens M, 2011. Osmotic responses of different strains of Steinernema carpocapsae. Nematology 13, 845-851.

Zhang ZR, Cao L, Liu XL, Wang GH, Xu ZF \& Han RC, 2006. Screening of insecticides as synergists for entomopathogenic nematodes Steinernema longicaudum X-7. Chinese Bull Entomol 43 (1), 68-73. 